\title{
População, espaço e ambiente: por uma demografia da adaptação às mudanças climáticas globais
}

\author{
Douglas Sathler
}

\begin{abstract}
MARTINE, G.; SCHENSUL, D. (Eds.). The demography of adaptation to climate
change. New York, London and Mexico City: UNFPA, IIED and El Colegio de México, 2013.
\end{abstract}

O quinto relatório do Painel Intergovernamental sobre Mudanças Climáticas (AR5-IPCC) já está na fase final de preparação, com divulgação prevista entre setembro de 2013 e novembro de 2014. O AR5 deverá trazer avanços na compreensão dos impactos socioeconômicos das mudanças climáticas e suas implicações para o desenvolvimento sustentável. Entretanto, não está claro ainda qual será o peso dado às questões demográficas neste relatório. Nas versões anteriores, apesar de as projeções populacionais constituírem, implícita ou explicitamente, a espinha dorsal dos cenários referentes às emissões, a questão populacional não foi devidamente incorporada pelos IPCCS. Assim, os padrões de crescimento diferenciados e processos determinantes, como a urbanização ou o envelhecimento populacional, estão diluídos em análises muito superficiais. Isto parece refletir uma relutância generalizada no enfrentamento do debate político e ideológico que costuma dominar os temas de crescimento e distribuição populacional no cenário global. Esta falta de desagregação e de detalhamento nas análises demográficas tem debilitado os relatórios, diante das dificuldades na atribuição de causalidades e na sugestão de políticas incisivas.

Neste contexto, é fundamental convencer os policymakers globais, nacionais ou locais a respeito do papel estratégico da dinâmica demográfica na etiologia das mudanças climáticas e de como o conhecimento das tendências referentes a crescimento, distribuição e composição da população é essencial para orientar as políticas de mitigação e adaptação a estes fenômenos. Neste sentido, o livro intitulado The demography of adaptation to climate

\footnotetext{
* Faculdade Interdisciplinar em Humanidades - FIH/Núcleo de Geociências - Nugeo, da Universidade Federal dos Vales do Jequitinhonha e Mucuri - UFVJM, Diamantina-MG, Brasil (doug.sathler@gmail.com).
} 
change, editado por George Martine e Daniel Schensul, está na vanguarda dos estudos que procuram explicitar a importância das contribuições da demografia na busca por estratégias e políticas eficientes. Os editores observam que as políticas de adaptação às mudanças climáticas globais exigem uma atenção redobrada. Na visão deles, mesmo que, nas próximas décadas, a humanidade se esforce com afinco para transformação dos padrões de produção e consumo, e com adoção de medidas universais de mitigação, os impactos das mudanças climáticas globais ainda demandarão iniciativas de adaptação.

Na publicação, argumenta-se que entender e reduzir a vulnerabilidade climática estão no centro de uma adaptação efetiva. Isto exige uma atitude proativa, contrastando com as ações post-hoc e remediais que costumam dominar esta área. Os editores afirmam que a falta de informações básicas frequentemente explica ou até justifica a ausência de políticas eficazes. Assim, o uso apropriado de informações demográficas é essencial para orientar novas abordagens, tendo em vista que as projeções populacionais geralmente oferecem os cenários mais confiáveis referentes a tamanho, estrutura, localização e características das necessidades de adaptação.

Por outro lado, eles sugerem que é necessário um amplo entendimento das principais mudanças sociais, no intuito de evitar perspectivas superficiais e determinísticas sobre a relação população e ambiente. O conhecimento da dinâmica demográfica não somente facilita antecipar as necessidades de adaptação, mas também orienta ações mais efetivas. Conforme os editores, o caminho para a adaptação nas próximas décadas deve assumir definitivamente a perspectiva humana, colocando em primeiro plano questões relativas ao bem-estar e aos direitos das populações e comunidades vulneráveis.

O livro demonstra como a dinâmica populacional e as variáveis de interesse direto da demografia assumem papel central nas discussões sobre os meios de subsistência, localização, vulnerabilidade econômica, vulnerabilidade ambiental e resiliência, além de esclarecer que o entendimento da dinâmica demográfica traz importantes contribuições para a superação das percepções estáticas sobre a vulnerabilidade. Assim, mudanças no tamanho, na distribuição espacial, na estrutura etária e na composição das famílias também afetam a natureza da vulnerabilidade e os tipos de respostas naturais ou antrópicas às futuras transformações climáticas do planeta.

O livro foi dividido em três seções: 1) Dinâmica populacional e adaptação: conceitos-chave e perspectivas; 2) Dados populacionais para adaptação: fontes e metodologias; 3) O planejamento e a prática da adaptação. A primeira traz importantes contribuições reflexivas e teóricas sobre o assunto. Os conceitos centrais em torno do tema da adaptação são explicitados e os benefícios da incorporação da dinâmica populacional no desenho das estratégias de adaptação são tratados de forma mais explícita no capítulo 1, produzido por Schensul e Dodman. Em seguida, McGranhan analisa mais especificamente as consequências do avanço da urbanização em tempos de mudanças climáticas, enquanto Tacoli avalia mitos e realidades em relação à migração causada por transformações ambientais. 
A segunda seção do livro pode ser vista como a mais inovadora e, ao mesmo tempo, a mais prática em termos de oferecer sugestões concretas para a utilização de dados demográficos para orientar a análise e a programação nos trabalhos de adaptação. Guzmán et al. situam o potencial metodológico dos dados censitários na elaboração e análise de indicadores, enquanto Balk et al. sugerem como utilizar os dados censitários em conjunto com os SIGs para enfocar áreas menores e superar as limitações de fronteiras administrativas. Landy e Fuchs mostram como integrar dados de surveys para cobrir as limitações dos dados censitários nos esforços de adaptação.

A última seção apresenta exemplos concretos de como os conceitos, dados e técnicas da demografia podem ajudar a cunhar estratégias mais proativas de adaptação. Schensul et al. mostram como a análise espacial baseada em dados censitários pode alimentar a formulação de políticas, mesmo em um país pobre e vulnerável como Malawi. Martine e Ojima argumentam que o processo de urbanização massiva delimita, na atualidade, o campo mais importante para atitudes proativas de adaptação e exemplificam isso com o estudo de caso brasileiro. Graizbord utiliza tecnologias sofisticadas para identificar graus e especificidades de vulnerabilidade na megacidade do México, demonstrando como as causas principais dos problemas socioambientais nesta metrópole estão associadas à má gestão no uso da terra.

Assim, o livro reuniu esforços de pesquisadores de várias instituições e enfoca uma variedade de temas abordados em diferentes níveis de generalidade - o que constitui sua força e sua debilidade. Para a comunidade de demógrafos e geógrafos, por exemplo, talvez os temas “concretos" da segunda seção merecessem um livro inteiro. De qualquer forma, mesmo com a diversidade descrita anteriormente, o livro representa uma importante iniciativa, tanto para estimular o uso do instrumental demográfico nas questões relacionadas às mudanças climáticas, como para demonstrar a necessidade de maior e melhor atenção às questões de adaptação. A obra é disponibilizada gratuitamente no site da UNFPA, o que amplia o poder de alcance da publicação e contribui para a democratização do acesso ao conhecimento científico recente sobre população, espaço e ambiente.

\section{Autor}

Douglas Sathler é Geógrafo formado pelo IGC-UFVJM, doutor em Demografia (Cedeplar-UFMG) e professor da Universidade Federal dos Vales do Jequitinhonha e Mucuri.

Recebido para publicação em 11/11/2013 Aceito para publicação em 03/12/2013 